\title{
O Direito Ambiental e os Novos Paradigmas do Direito Econômico: a Ascensão do Estado Regulador
}

\section{Environmental Law and the New Paradigms of Economic Law: the Rise of the Regulatory State}

Ana Paula Vasconcellos da Silva ${ }^{1}$

\begin{abstract}
Resumo:
O presente trabalho buscou, primeiramente, traçar pressupostos teóricos quanto ao Direito Econômico. Argumentou-se, inicialmente, que o Direito Ambiental, além de pertencer ao campo dos direitos fundamentais, pertence à esfera do Direito Econômico. Em seqüência, defendeu-se que o Direito Econômico encontra-se em transformação graças à ascensão do Estado Regulador e seu principal instrumento, as Agências Reguladoras, além dos novos paradigmas do Direito Administrativo na ordem jurídica brasileira. Tal transformação pode ser utilizada para que se dê uma nova perspectiva à defesa do meio ambiente, especialmente orientada pelos princípios da prevenção e da precaução, buscando uma atuação mais eficiente do Estado na proteção do patrimônio ambiental.
\end{abstract}

Palavras-chave: Direito Ambiental; Direito Econômico; Regulação.

\begin{abstract}
:
This paper presented a theoretical base to discuss the actual Economics Law. Firstly, it was discussed that Environmental Law, more than belonging to human rights, belongs also to Economics Law. Also, the Economics Law goes through a deep changing process, as the Regulatory State rises in Brazil, especially with the empowerment of the Regulatory Agencies. At the same time, one may observe a changing of Administrative Law in Brazilian nowadays context. Thus, this changing may be used as a new approach of environmental defense, especially by using precautionary principle, a new performance of State can be developed, mainly in a more efficient protection of natural goods.
\end{abstract}

Key Words: Environmental Law; economics Law; Regulation;

\section{1 - INTRODUÇÃO: A PROTEÇÃO DO MEIO AMBIENTE NA LEGISLAÇÃO NACIONAL}

A proteção ao meio ambiente é assunto que ganhou grande espaço ao final do século $\mathrm{XX}$, e recentemente vem aparecendo quase que com estardalhaço na mídia e nas produções acadêmicas, especialmente devido à urgente - e talvez tardia - preocupação com o efeito estufa $^{2}$.

\footnotetext{
${ }^{1}$ UERJ - Mestranda em Direito das Cidades - anapaulavas@yahoo.com.br

${ }^{2}$ Apenas à guisa de ilustração, o Jornal do Brasil publica mensalmente há 5 anos o especial "JB Ecológico", cuja tema exclusivo é o meio ambiente. A Revista Época passou a publicar semanalmente o especial "Pense Verde", sem contar as inúmeras reportagens especiais sobre o aquecimento global e o recente documentário "Uma Verdade Inconveniente", de Al Gore.
} 
Tal proteção, contudo, reveste-se de um caráter especial, visto que é um direito cujo titular não é necessariamente determinado. De fato, o destinatário deste direito é toda a humanidade, incluindo aqueles que ainda não estão aqui - preceito consagrado com o princípio da responsabilidade entre gerações, pois aqueles que aqui estão hoje não podem utilizar o meio ambiente de forma a provocar a sua escassez para as gerações vindouras.

No entanto, embora venha sendo tratado de forma mais intensa nos últimos anos, o tema da proteção ao meio ambiente remonta a tempos antigos. Segundo Édis Milaré ${ }^{3}$, desde a Bíblia já havia orientações quanto à proteção ao meio ambiente, tanto no Gênesis quanto no Deuteronômio. Ainda segundo este autor, mesmo no Brasil já existia legislação protetiva desde o descobrimento até a entrada em vigor do Código Civil, em 1916. Eram as Ordenações Afonsinas, Manuelinas e Filipinas, que vigoravam em Portugal, mas que também eram válidas para as colônias portuguesas.

Tais normas, no entanto, eram confusas, esparsas e inadequadas, e, longe de proteger o meio ambiente, permitiu que este fosse explorado inescrupulosamente, até o ponto em que sistemas naturais inteiros fossem praticamente extintos ${ }^{4}$.

Após a independência do Brasil, autores como José Bonifácio de Andrada e Silva e Joaquim Nabuco preocuparam-se, entre ouros ideais, com a defesa dos elementos da natureza. Porém, conforme destaca Milaré, "nossa história, infelizmente, é de uma depredação ambiental impune. Na prática, somente eram punidos os delitos que atingissem a Coroa ou os interesses fundiários das classes dominantes". . Assim, durante a fase imperial e o início da República, a utilização indiscriminada dos recursos naturais não era sistematicamente tratada pelo ordenamento jurídico, e sua punição, quando existia, obedecia a interesses que não a efetiva proteção ambiental.

Após a proclamação da República e a edição do Código Civil de 1916, começam a aparecer os primeiros diplomas legais destinados especificamente à proteção da Natureza ${ }^{6}$. No entanto, conforme destaca o autor supramencionado, somente a partir da década de 1980 é que a legislação sobre a matéria passou a se desenvolver com maior sistematicidade e celeridade.

\footnotetext{
${ }^{3}$ MILARÉ, Édis. Direito do Ambiente: Doutrina - Jurisprudência - Glossário. $4{ }^{\text {a }}$ Edição. São Paulo: Editora Revista dos Tribunais, 2005. Páginas 134 e seguintes.

${ }^{4}$ A Mata Atlântica é um exemplo paradigmático desta falha: originalmente, cobria todo o litoral brasileiro, mas hoje resta apenas $5 \%$ da extensão original.

${ }^{5}$ Obra citada, p. 138.

${ }^{6}$ Para uma lista completa destes diplomas, remetemo-nos a obra de Edis Milaré já citada, página 140.
} 
Ainda segundo este doutrinador ${ }^{7}$, existiram 4 marcos legislativos que corroboram a mudança de mentalidade do legislador brasileiro, que foram:

(i) - Lei 6938/81, Lei da Política Nacional do Meio Ambiente, que instituiu o Sistema Nacional do Meio Ambiente (SISNAMA);

(ii) - Lei 7347/85, que disciplinou a Ação Civil Pública, principal instrumento processual para a proteção do meio ambiente;

(iii) - Constituição de 1988, que consolidou a proteção ao ambiente ao destacar um capítulo inteiro para tratar do tema;

(iv) - Lei 9605/98, lei dos Crimes Ambientais, que tem por mérito sistematizar as sanções penais, oferecer uma lógica orgânica aos crimes ambientais e inovar no ordenamento jurídico com a inclusão da pessoa jurídica como sujeito ativo nos crimes ambientais.

Dos 4 marcos apresentados por Milaré, nos focaremos mais adiante na Constituição Federal de 1988. Por ora, basta perceber a partir desta breve retrospectiva histórica que sempre existiram normas que regulamentavam o uso dos recursos naturais. Porém, o objetivo que orienta o agente normatizador varia bastante conforme o tempo. Do mesmo entendimento é Paulo de Bessa Antunes:

Sempre houve normas voltadas para a tutela da natureza. Tal proteção, quase sempre, fazia-se através de normas de Direito Privado, que protegiam as relações de vizinhança, ou mesmo por normas de Direito Penal ou Administrativo, que sancionavam o mau uso dos elementos naturais ou a utilização destes que pudesse causar prejuízos ou incômodos a terceiros. Entretanto, a problemática suscitada pelos novos tempos demanda uma outra forma de conceber a legislação de proteção à natureza. As antigas formas de tutela propiciadas pelo Direito Público ou pelo Direito Privado são insuficientes para responder à uma realidade qualitativamente diversa. ${ }^{8}$

E também Paulo Leme Affonso Machado:

Prevenir a degradação do meio ambiente no plano nacional e internacional é concepção que passou a ser aceita no mundo jurídico especialmente nas ultimas três décadas. Não se inventaram todas as regras de proteção ao ambiente humano nesse período. A preocupação com a higiene urbana, um certo controle sobre as florestas e a caça já datam de séculos. Inovou-se no tratamento jurídico dessas questões, procurando integrá-las e sistematizá-las, evitando-se a fragmentação e até o antagonismo de leis, decretos e portarias. ${ }^{9}$

\footnotetext{
${ }^{7}$ Obra citada, paginas 141-142.

${ }^{8}$ ANTUNES, Paulo de Bessa. Direito Ambiental. 9a Edição. Rio de Janeiro: Editora Lúmen Júris, 2006. P. 3

${ }^{9}$ MACHADO, Paulo Affonso Leme. Direito Ambiental Brasileiro. 14 Edição. São Paulo: Malheiros Editores, 2006, p. 61 .
} 
Assim, os reais objetivos que orientaram a construção das legislações ambientais acabam por refletir na capacidade que estas normas têm de interagir com o restante do ordenamento jurídico, ou seja, sua sistematicidade, e no grau de eficácia que elas terão dentro daquela sociedade naquele momento histórico.

Há que se compreender que o homem é elemento tão essencial para a natureza quanto todos os seres vivos, e não é possível dissociar o ser humano do meio ambiente. Aliás, muito acertadamente Paulo de Bessa Antunes esclarece que não há conceito de natureza sem o homem, assim como não há cultura humana sem natureza ${ }^{10}$. Enxergar os seres humanos como seres aparte da natureza isentaria a todos nós da responsabilidade conjunta que temos pelo destino do planeta, tornando a sociedade indiferente para os desígnios dos demais seres vivos. É esse, também, o pensamento de Antunes, que assim expressa suas idéias:

\begin{abstract}
No momento em que o Homem começou a se ver como externo à Natureza, esta morreu. Penso que o problema central, que não tem sido enfrentado com a extensão que merece, é o do significado da apropriação social do fim da natureza. Foi socialmente que a natureza acabou e deve ser socialmente que as alternativas para os problemas ambientais devem ser buscadas. ${ }^{11}$
\end{abstract}

É a concepção de natureza presente na sociedade que orientará a formação das normas para o uso dos elementos naturais; e também será a sociedade que determinará o grau de eficácia que essas normas terão. A participação popular será fundamental nas soluções que proporemos sobre o tema nos capítulos seguintes; por esta razão é importante que esta idéia fique clara desde já.

Feita esta pequena introdução, e esgotado o tema da inaplicabilidade do preservacionismo, vislumbra-se que a terceira acepção é a que vem se mostrando mais eficaz no momento da elaboração e consecução de normas de proteção à natureza. Não por acaso esta é a corrente atualmente dominante nas legislações da maior parte dos países, e que alcança seu ápice com a concepção do Direito Ambiental como parte integrante do Direito Econômico e também dos Direitos Humanos Fundamentais. Os desdobramentos dessa concepção, e como as legislações e doutrina atuais refletem este pensamento, serão o objeto de estudos deste trabalho.

\title{
2 - DIREITO AMBIENTAL: POSSIBILIDADES DE LEITURA
}

\footnotetext{
${ }^{10}$ Obra Citada, Capítulo 1.

${ }^{11}$ Obra Citada, p. 124.
} 


\section{1 - O DIREITO AMBIENTAL COMO DIREITO ECONÔMICO E COMO DIREITO FUNDAMENTAL}

Antes de apresentar os argumentos doutrinários acerca do tema, façamos uma breve reflexão acerca do termo "ecologia".

"Ecologia" é palavra formada pelo termo "oikos", que significa "casa", e por "logos" (logia), que significa ciência, estudo. Assim, de forma bem simples, ecologia significa a ciência que estuda a nossa casa, o planeta Terra. Há, no entanto, outra ciência que possui uma formação vocabular semelhante: a Economia.

E não se trata de mera coincidência: "oikos", que significa "casa" é complementado por "nomia", que significa gerenciamento, organização. Portanto, Ecologia e Economia são ciências relacionadas ao mesmo objeto de estudo, tendo tão-somente focos distintos. Essa conexão, embora pareça óbvia pela abordagem dos vocábulos, não é tão facilmente aceita. É Paulo de Bessa Antunes, que uma vez mais tomamos a liberdade de transcrever, quem constata que "infelizmente, o ponto de vista de muitas pessoas é que ecólogos e economistas são adversários, com visões antitéticas" ${ }^{\prime 12}$.

A ligação entre Ecologia e Economia não é mero acaso filológico. Esta pequena reflexão apresentada por Paulo de Bessa Antunes nos faz perceber que, de fato, existe uma ligação muito forte entre a defesa do meio ambiente e o uso dos recursos naturais para a produção industrial e desenvolvimento econômico. Conforme já dissemos anteriormente, não é possível dissociar o homem - e suas necessidades - da natureza. Porém, também não há que se permitir que as intermináveis necessidades humanas consumam todo o planeta.

Portanto, é preciso chegar a um ponto de equilíbrio, em que o respeito pelos demais seres vivos, as necessidades de desenvolvimento econômico e os direitos humanos fundamentais de todas as culturas sejam respeitados - essa a fórmula que todos nós, juristas, economistas, sociólogos, antropólogos, biólogos, cada um em sua especialidade, devemos buscar.

Juridicamente, essa convergência é construída ao se pensar o Direito Ambiental como um dos ramos do Direito Econômico e também como parte dos Direitos Humanos Fundamentais. Essa construção é defendida fundamentalmente por Paulo de Bessa Antunes, que resume de maneira bem sintética seu pensamento com a frase:

\footnotetext{
${ }^{12}$ Citando Eugene Odum. Obra. Citada, p. 148.
} 
O Direito Ambiental, portanto, tem uma dimensão humana, uma dimensão ecológica e uma dimensão econômica que se devem harmonizar sob o conceito de desenvolvimento sustentável. ${ }^{13}$

Este entendimento de que o Direito Ambiental deve fazer parte tanto do rol dos direitos fundamentais como ser tratado pelo seu aspecto econômico não é exclusivo deste ambientalista. Ele encontra ecos também entre doutrinadores de outros ramos do Direito, como por exemplo, Ricardo Lobo Torres:

O desenvolvimento econômico deve ser justo para que se torne legítimo. Não é ele que cria uma ordem econômica justa, senão que o ordenamento justo é que propicia as condições para o desenvolvimento. Em nome do crescimento econômico, não se pode postergar a redistribuicão de rendas, nem ofender aos direitos humanos, nem atentar contra o meio ambiente, nem justificar a corrupção dos políticos. Sendo questão de justiça, a problemática do desenvolvimento econômico não se deixa aprisionar pelo cálculo utilitarista, embora não lhe seja estranha a consideração do

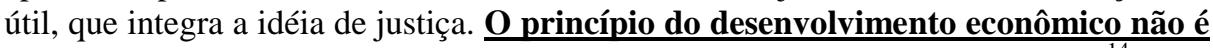
um fim em si mesmo, mas deve se afinar com o desenvolvimento humano." (...)

Conceito mais próximo dos direitos humanos é o de desenvolvimento humano, que vem sendo discutido sob os auspícios da ONU, especialmente na forma de desenvolvimento humano sustentável, em íntima relação com o meio ambiente sadio e com os direitos das geracõos futuras. ${ }^{15}$ (grifos nossos)

Aqui também encontramos a proteção ao meio ambiente como interseção entre os direitos humanos e o desenvolvimento econômico. Nesse mesmo sentido também advoga Eros Grau em seu já clássico A Ordem Econômica na Constituição de 1988:

O princípio da defesa do meio ambiente conforma a ordem econômica (mundo do ser), informando substancialmente os princípios da garantia do desenvolvimento e do pleno emprego. Além de objetivo, em si, é instrumento necessário - e indispensável - à realização do fim desta ordem, o de assegurar a todos existência digna. Nutre também, ademais, os ditames da justiça social. Todos têm direito ao meio ambiente ecologicamente equilibrado, bem de uso comum do povo diz o art. 225, caput, da Constituição.

O desenvolvimento nacional que cumpre realizar, um dos objetivos da República Federativa do Brasil, e o pleno emprego que impende assegurar supõem economia auto-sustentada, suficientemente equilibrada para permitir ao homem reencontrar-se consigo próprio, como ser humano, e não apenas como dão ou índice econômico. (grifos nossos)

Percebe-se que doutrinadores de áreas distintas do Direito convergem para a conclusão de que não é possível pensar o desenvolvimento econômico sem a proteção ao meio ambiente e sem respeito aos direitos humanos. No entanto, também não é possível pensar a proteção ao ambiente impedindo o desenvolvimento econômico, visto que a melhora dos indicadores

\footnotetext{
${ }^{13}$ ANTUNES, Paulo de Bessa. Direito Ambiental. $9^{a}$ Edição. Rio de Janeiro: Editora Lúmen Júris, 2006. P. 11.

${ }^{14}$ TORRES, Ricardo Lobo. Tratado de Direito Constitucional Financeiro e Tributário. Volume II - Valores

e Princípios Constitucionais Tributários. Rio de Janeiro: Ed. Renovar, 2005. P. 350

${ }^{15}$ Obra citada, páginas 352-353

${ }^{16}$ GRAU, Eros. A Ordem Econômica na Constituição de 1988. 11 edição. São Paulo: Malheiros Editores, 2006. P. 251.
} 
econômicos de um país é essencial para que outros direitos fundamentais também sejam efetivados, como por exemplo, o acesso ao trabalho como forma de se garantir uma existência digna.

Aliás, a compreensão de que um meio ambiente equilibrado como parte dos direitos humanos fundamentais é pacífica, tendo sido assim reconhecido pela Conferência de Estocolmo, de 1972, reafirmado durante a ECO 92, no Rio de Janeiro, e pela Carta da Terra, em 1997.

Além, é claro, do seu reconhecimento em sede constitucional, que, apesar de não estar topograficamente localizado dentro do título de Direitos e Garantias Individuais, não perde em conteúdo, visto que o art. $5^{\circ}, \S 2^{\circ}$, admite a existência de outros direitos fundamentais decorrentes do regime e dos princípios adotados pela Carta Magna além daqueles tipificados ao longo do Título de Direitos e Garantias Individuais.

A dificuldade encontra-se mesmo na aceitação de que a proteção do meio ambiente deve ser considerada no desenvolvimento econômico e vice-versa, como bem demonstra a corrente do preservacionismo que explicitamos anteriormente. Porém, não perceber o conteúdo econômico dos bens ambientais não irá preservá-los dos danos - apenas fará com que a exploração seja feita às escondidas, à margem da fiscalização do Estado. E é justamente por estar à margem da normatização e fiscalização estatal é que a atividade econômica se torna mais predatória e inescrupulosa.

Conforme bem destaca Paulo de Bessa Antunes em sua teoria sobre o dano ambiental:

\begin{abstract}
Não perceber a fortíssima presença das diferentes pressões econômicas nas questões relativas ao meio ambiente, em minha opinião, significa permitir que elas ajam sem controle e em claro prejuízo ao meio ambiente e à qualidade de vida. De fato, é extremamente necessário que o tratamento econômico das questões ambientais seja feito sem preconceito e abertamente, pois a renúncia em empreender tal abordagem não implica que a problemática econômica se retire das questões referentes ao meio ambiente; ao contrário, implica que a perspectiva econômica se apresente de forma imediatista e, destarte, sem os necessários cuidados ambientais, como tem sido comprovado diariamente. Aliás, o jurista brasileiro não se pode furtar a enfrentar o espinhoso tema das relações entre economia e ambiente, vez que, em sede constitucional, a matéria está plenamente caracterizada como de natureza econômica, embora não se restrinja a isso. (grifos nossos) ${ }^{17}$
\end{abstract}

Felizmente, a compreensão de que o meio ambiente também deve ser pensado como fator explorável economicamente, e não apenas como direito fundamental, vem ganhando um número cada vez maior de adeptos - em especial após a vigência da Carta Constitucional de 1988, que fez referência explícita à proteção ambiental no título relativo à Ordem Econômica.

\footnotetext{
${ }^{17}$ ANTUNES, Paulo de Bessa. Dano Ambiental: Uma Abordagem Conceitual. 1a Edição. Rio de Janeiro:
} Editora Lúmen Júris, 2002. P. 201. 
Pensar o meio ambiente em sua acepção econômica não significa perder de vista a acepção social dos recursos naturais - em especial quanto aos conflitos sócio-ambientais que geralmente os envolvem, em especial naqueles que são economicamente mais desejáveis. Estes dois aspectos não podem ser dissociados - e os próprios agentes econômicos parecem ter cada vez mais ciência disso. É o que constata Peter May, acadêmico de renome em questões ambientais, e que passamos a transcrever:

\begin{abstract}
As respostas corporativas às demandas da sociedade, para um desenvolvimento sustentável, vêm aumentando a percepção de que este representa uma convenção de mercado, influenciando os parâmetros da competição em um contexto cada vez mais global. Para ter uma participação efetiva no mercado, nesse contexto globalizado, as indústrias devem buscar opções tecnológicas mais amenas, assim como procurar meios para reforçar relações de benefício mútuo com as comunidades vizinhas. (Vinha, 2000). ${ }^{18}$
\end{abstract}

Portanto, a nova Carta Constitucional acertou ao trazer a proteção ambiental como elemento constituinte da ordem econômica brasileira. Mas o jurista, ao aplicar o comando constitucional, deve estar atento aos fatores de conflito social envolvendo a utilização econômica da natureza, integrando os fatores sociais com a mudança de pensamento que a Carta Magna desejou implementar - mudança essa que será demonstrada a seguir.

\title{
2.2 - O DIREITO AMBIENTAL NA CONSTITUIÇÃO DE 1988
}

A Constituição de 1988, além de dispensar um capítulo inteiro à proteção ao meio ambiente (embora o capítulo seja composto unicamente pelo artigo 225), consagrando o bem ambiental como bem de uso comum do povo ${ }^{19}$, buscou também estabelecer uma harmonia entre os dispositivos que disciplinam a sua utilização.

Essa harmonia busca integrar as normas de natureza econômica e aquelas destinadas à proteção dos direitos fundamentais, alcançando seu ápice ao consagrar a proteção ao meio ambiente como um dos fundamentos da ordem econômica brasileira, no seu art. 170, VI, conforme segue abaixo:

Art. 170 - A ordem econômica, fundada na valorização do trabalho humano e na livre iniciativa, tem por fim assegurar a todos existência digna, conforme os ditames da justiça social, observados os seguintes princípios:

I - soberania nacional;

\footnotetext{
18 MAY, Peter. Certificação Florestal No Brasil: Valorização Comercial e Ambiental. Em http://www.wto.org/english/forums_e/ngo_e/ccc_cert_forest_brazil_p.doc. Acesso em janeiro de 2008.

${ }^{19}$ Há autores como Celso Antonio Pacheco Fiorillo que defendem que as relações de propriedade tradicionais não se aplicam aos bens ambientais, dada a sua natureza jurídica de bem de uso comum do povo - nesse sentido, confira-se o seu artigo A Natureza Jurídica do Bem Ambiental, disponível em http://www.fiorillo.com.br/site/. Acesso em janeiro de 2008.
} 
II - propriedade privada;

III - função social da propriedade;

IV - livre concorrência;

V - defesa do consumidor;

VI - defesa do meio ambiente, inclusive mediante tratamento diferenciado conforme o impacto ambiental dos produtos e serviços e de seus processos de elaboração e prestação; (Alterado pela EC 42-2003)

VII - redução das desigualdades regionais e sociais;

VIII - busca do pleno emprego;

IX - tratamento favorecido para as empresas de pequeno porte constituídas sob as leis brasileiras e que tenham sua sede e administração no País.

O artigo 170, por si só, já demandaria um estudo aprofundado para que se explicitasse qual é a mens legis de um comando normativo que conjuga em si valores aparentemente tão conflitantes como "livre concorrência" e "tratamento favorecido para empresas de pequeno porte", ou ainda "defesa do meio ambiente" e "busca do pleno emprego" ${ }^{20}$. Aliás, essa idiossincrasia aparente não passou despercebida por Diogo de Figueiredo Moreira Neto, que critica a redação do art. 170 da Carta Magna, ao afirmar que "a redação desse artigo tem o vício típico dos produtos dos grandes colegiados, que, em áreas de transigências recíprocas, acabam por sacrificar até a lógica". ${ }^{21}$

No entanto, no nosso assentir, não há que se enxergar vício na interpretação do art. 170 da Constituição, dado que o texto constitucional nos oferece princípios que devem ser ponderados diante da prática econômica. Está é a opinião do professor Mukai, com quem concordamos, e que passamos a transcrever a seguir:

\begin{abstract}
Entendemos que não existe possibilidade jurídica de haver 'conflitos' entre os princípios arrolados pelo art. 170 da Constituição de 1988. (...)

A Constituição, ao contemplar no mesmo plano os princípios da livre concorrência e o da defesa do meio ambiente, não admite que este último seja colocado de lado, com privilégio do primeiro.

Há que se compatibilizar, sempre e a todo custo, os dois princípios. E, em caso de conflito real, há que se efetuar uma ponderação de interesses, para que não haja o sacrifício total de um ou do outro. ${ }^{22}$
\end{abstract}

Portanto, nos parece que o texto constitucional, ao aproximar conceitos tão díspares quanto o da livre iniciativa e da proteção ao meio ambiente, não tinha por intenção apenas fazer concessões aos diversos segmentos sociais representados na Assembléia Constituinte. $\mathrm{Na}$ verdade, ele reconhece a existência e a importância dessas intenções aparentemente antagônicas, e consagra que a ordem econômica que deve ser construída pelo Estado

\footnotetext{
${ }^{20}$ Para um estudo mais amplo sobre o tema, recomendamos o já citado A Ordem Econômica na Constituição de 1988, de Eros Grau.

${ }^{21}$ MOREIRA NETO, Diogo de Figueiredo. Ordem Econômica e Desenvolvimento na Constituição de 1988. Citado por MUKAI, Toshio. Direito Ambiental Sistematizado. $6^{a}$ Edição. Rio de Janeiro: Forense Universitária, 2007, pgn. 30

${ }^{22}$ Op. Citada, pgns. 32-34
} 
brasileiro irá ponderar as necessidades desenvolvimentistas com as necessidades de conservação do meio ambiente, respeitando, sempre, a existência digna e a justiça social.

Destarte, este dispositivo constitucional consagra o entendimento doutrinário que temos defendido neste trabalho. A positivação em sede constitucional já está feita, elencando subitens genéricos para a construção da ordem econômica. Cabe agora aos operadores do Direito realizar essa ponderação na prática, de forma que nem o desenvolvimento econômico nem a proteção ambiental sejam totalmente suprimidos ou atinjam um caráter absoluto.

\section{3 - O DIREITO AMBIENTAL COM OS PRINCÍPIOS DA PRECAUÇÃO E DA PREVENÇÃO COMO PARADIGMA}

A questão do Direito Ambiental, seja em âmbito constitucional, seja como interseção entre o Direito Econômico e os Direitos Humanos Fundamentais, é um tema vastíssimo e que precisa mesmo ser enfrentado não só pelos juristas, mas também por sociólogos e economistas. No entanto, para os fins a que se destinam este trabalho, basta-nos lançar as premissas teóricas já discutidas até aqui. Há apenas um último referencial teórico a ser trabalhado antes que passemos para o próximo item deste capítulo.

Conforme já dissemos anteriormente, a proteção ao meio ambiente ganhou grande reforço em solo nacional com a Constituição de 1988, que, além de consagrar o que Paulo Affonso Leme Machado chama de ética da solidariedade entre as gerações ${ }^{23}$, consagra também três tipos de responsabilidade para o dano ecológico, que são independentes entre si: a administrativa, a criminal e a civil - o que, segundo José Afonso da Silva, "não é peculiaridade do dano ecológico, pois qualquer dano a bem de interesse público pode gerar os três tipos de responsabilidade". ${ }^{24}$

Contudo, essas três esferas de atuação para a reparação ao dano ecológico vêm se mostrando ineficazes para a proteção ao meio ambiente. Sem entrar no mérito da eficiência da atuação do Poder Público nestas respectivas searas jurídicas - o que fugiria ao escopo deste trabalho -, estes instrumentos protetivos não são suficientes justamente porque lidam apenas com a reparação do dano ambiental - ou seja, a intervenção do Estado só se dará depois que a lesão ao meio ambiente tiver ocorrido.

\footnotetext{
${ }^{23}$ MACHADO, Paulo Affonso Leme. Direito Ambiental Brasileiro. 14 ${ }^{\text {a }}$ Edição. São Paulo: Malheiros Editores, 2006, pgn. 123

${ }^{24}$ SILVA, José Afonso da. Direito Ambiental Constitucional. 5a Edição. São Paulo: Editora Malheiros, 2004. pgn. 300
} 
No entanto, o operador do Direito não pode se dar ao luxo de apenas tentar retornar ao status quo ante, pois, dada a fragilidade e a complexidade que a questão demanda, restaurar o que foi perdido mostra-se uma tarefa árdua - e muitas vezes impossível.

Aliás, é em decorrência do Princípio da Efetividade, norteador dos atos da Administração Pública, que o Estado deve centrar suas atenções na prevenção do dano ambiental. Assim, como didaticamente nos ensina Ruanda Schilickman Michelis em seu artigo Instrumentos Administrativos de Prevenção ao Dano Ambiental, publicado na Revista de Direito Ambiental no 45:

\begin{abstract}
A prevenção do dano é reconhecida unanimemente como sendo o objetivo fundamental do Direito Ambiental. Isso porque, ocorrido um dano, na grande maioria das vezes nenhum tipo de reparação terá a capacidade de fazer com que o meio ambiente volte ao seu status quo ante, isto é, que seja restabelecida, em igualdade de condições, uma situação idêntica à anterior. $^{25}$
\end{abstract}

Portanto, a proteção ao meio ambiente deve mostrar-se não apenas na efetiva punição daqueles que causaram o dano, mas principalmente na prevenção de lesões. A Conferência das Nações Unidas para o Meio Ambiente, reunida em 1992, consagrou pelo menos dois princípios nesse sentido: o princípio da precaução e o princípio da prevenção. Em especial em relação a este último, Paulo Affonso Leme Machado o divide em 05 itens de aplicação:

\begin{abstract}
(i) Identificação e inventário das espécies animais e vegetais de um território, quanto à conservação da natureza e identificação das fontes contaminantes das águas do mar, quanto ao controle da poluição;
\end{abstract}

(ii) Identificação e inventário dos ecossistemas, com a elaboração de um mapa ecológico;

(iii) Planejamentos ambiental e econômico integrados;

(iv) Ordenamento territorial ambiental para a valorização das áreas de acordo com a sua aptidão;

(v) Estudo de Impacto Ambiental. ${ }^{26}$ (grifos nossos)

Destacamos, uma vez mais, a presença do elemento econômico na construção dos pressupostos teóricos pertinentes ao Direito Ambiental. Aliás, o entendimento de que se deve compatibilizar o desenvolvimento econômico com a preservação ambiental foi consagrado pelo art. $4^{\circ}$, I, da Lei Federal n ${ }^{\circ}$ 6938/81, que instituiu a Política Nacional do Meio Ambiente, ao dispor que "a Política Nacional do Meio Ambiente visará à compatibilização do

\footnotetext{
${ }^{25}$ MICHELS, Ruanda Schlickmann Michels. Instrumentos administrativos de prevenção ao dano ambiental. Revista de Direito Ambiental 45. Rio de Janeiro: Editora Revista dos Tribunais, 2007.

${ }^{26}$ Obra Citada, p. 82.
} 
desenvolvimento econômico-social com a preservação da qualidade do meio ambiente e do equilíbrio ecológico”.

Nada mais natural: um desenvolvimento econômico bem planejado, que leve em consideração não apenas os fatores típicos da atividade econômica, mas também fatores sociais e ambientais, haverá de prevenir agressões desnecessárias à natureza. Em contrapartida, quanto mais se preservar o meio ambiente, mais recursos serão resguardados para a utilização futura. De mais a mais, considerar os direitos de populações economicamente menos poderosas permitirá que estes atores sejam também integrados no processo de desenvolvimento econômico, fazendo com que a região (e não apenas determinados segmentos sociais) se desenvolva como um todo. Uma vez mais nas palavras de Paulo de Bessa Antunes:

A natureza econômica do Direito Ambiental deve ser percebida como o simples fato de que a preservação e sustentabilidade da utilização racional dos recursos ambientais (que também, obviamente, são recursos econômicos) deve ser encarada de forma a assegurar um padrão constante de elevação da qualidade de vida dos seres humanos que, sem dúvida alguma, necessitam da utilização dos diversos recursos ambientais para a garantia da própria vida humana. O fator econômico deve ser encarado como desenvolvimento e não como crescimento, que é a simples acumulação de capital. ${ }^{27}$

No entanto, esse planejamento do desenvolvimento econômico, que leve em consideração os fatores econômicos, ambientais e sociais, tendo como norte a prevenção ao dano ambiental, não pode ser concebido por um destes atores sociais sozinho - seja o empreendedor, seja o indivíduo imerso naquela cultura, seja o responsável pela proteção ambiental. Para isso é preciso que o Estado realize esse planejamento, visto ser esta a sua função institucional, conforme consagrado na Constituição ${ }^{28}$. O Estado deve atuar como regulador da atividade econômica levando em consideração todos esses elementos - este o tema do nosso próximo item.

\section{3 - O DIREITO ECONÔMICO E O ESTADO REGULADOR}

\section{1 - A FALÊNCIA DO WELLFARE STATE E DO ESTADO INTERVENTOR}

Em 1995, com a elaboração do Plano Diretor da Reforma do Aparelho do Estado, elaborado pelo Ministério da Administração Federal e da Reforma do Estado - MARE -,

\footnotetext{
${ }^{27}$ ANTUNES, Paulo de Bessa. Direito Ambiental. 9a Edição. Rio de Janeiro: Editora Lúmen Júris, 2006. P. 23.

${ }^{28}$ Constituição Federal, art. 174: "Como agente normativo e regulador da atividade econômica, o Estado exercerá, na forma da lei, as funções de fiscalização, incentivo e planejamento, sendo este determinante para o setor público e indicativo para o setor privado."
} 
tivemos o marco legal de um processo que já vinha ocorrendo não apenas no Brasil, mas também no mundo inteiro.

Trata-se da construção de um novo modelo de Estado, dada a falência do modelo de Wellfare State que foi implementado ao redor do mundo após a Segunda Guerra Mundial. Este sistema de governo defendia um alargamento das estruturas estatais, em que o Estado passou a interferir fortemente no mercado, buscando manter permanentemente a economia acelerada para que os níveis de emprego estivessem sempre altos.

Esta política, defendida essencialmente por Keynes, embora socialmente muito benéfica, acabou gerando alguns problemas. Entre outros, podemos citar, apenas à guisa de ilustração: processos inflacionários galopantes, endividamento público excessivo, falta de recursos, por parte do Estado, para sustentar os projetos iniciados.

Em face desta conjuntura negativa, um novo modelo de Estado foi gradativamente sendo construído em meados da década de 1980, cujo carro-chefe era o fim ou a diminuição da participação do Estado em vários setores econômicos, incluindo os clássicos serviços públicos.

A diminuição da presença do Estado foi vista por muitos como um retorno ao liberalismo do séc. XVII, sendo este novo modelo batizado de "neoliberalismo". Embora as características desse novo modelo de gestão estatal ainda não possam ser totalmente compreendidas, sendo precoce ainda a definição de um modelo para a realidade hodierna, não se pode negar que houve um esvaziamento do Estado no plano econômico, além de uma intensificação do processo de globalização.

Estes fatores acabaram trazendo consequiências sociais nefastas, como por exemplo o crescimento do desemprego, o enfraquecimento dos direitos sociais conquistados anteriormente, a guerra fiscal entre países (e até mesmo dentro dos próprios países) e o fortalecimento excessivo dos controladores do capital.

Esta sumaríssima retrospectiva histórica é importante para que se perceba que houve, em fins da década de 80 e, principalmente na década de 90, o enfraquecimento da presença do Estado na economia. Este fenômeno é estudado por diversos campos das ciências humanas, sendo importante que se comparem os distintos pontos de vista para que se compreendam as peculiaridades deste fenômeno.

Por esta razão, trazemos à colação primeiramente o entendimento de Colin Leys, renomado economista, cujos estudos preocupam-se com a influência da globalização na governabilidade dos Estados: 
Agora, em toda a parte, a política é orientada para o mercado. Não se trata apenas de os governos não poderem mais 'administrar' suas economias nacionais; para sobreviver no cargo, devem 'administrar' cada vez mais a política nacional, de forma a adapta-la às pressões das forças de mercado multinacional. Essas pressões assumem muitas formas, tais como limites estritos à política macroeconômica, reivindicações de investidores por acordos de regulamentação favoráveis, impacto direto das forças econômicas globais em mercados específicos e a reforma 'profunda' e contínua das relações sociais e idéias por uma grande variedade de forças de mercado que agem com força cada vez maior graças à globalização. ${ }^{29}$

E, no mesmo sentido, Zygmunt Bauman, consagrado sociólogo que se dedica aos estudos da nossa líquida modernidade:

O derretimento dos sólidos [e a conseqüente fluidificação da sociedade] levou à progressiva libertação da economia dos seus tradicionais embaraços políticos, éticos e econômicos. Sedimentou uma nova ordem, definida principalmente em termos econômicos. Essa nova ordem deveria ser mais "sólida" que as ordens que substituía, porque, diferentemente delas, era imune a desafios por qualquer ação que não fosse a econômica. A maioria das alavancas políticas ou morais capazes de mudar ou reformar a nova ordem foram quebradas ou feitas curtas ou fracas demais, ou de alguma outra forma inadequadas para a tarefa. ${ }^{30}$ (grifos nossos)

Essa compreensão felizmente também foi absorvida por juristas. Em seu excelente trabalho sobre as Agências Reguladoras, Alexandre dos Santos Aragão assim destaca:

\footnotetext{
Paralela e simultaneamente aos desafios colocados pela globalização, o Estado atual sofre a crise do financiamento de suas múltiplas funções. Diante dela, ou a exemplo dos pensadores neoliberais, concluímos pela inevitabilidade da retração do Estado frente às necessidades sociais, ou pugnamos pela adoção de novas estratégias de atuação, compatíveis com a escassez de recursos. Apesar de não poder negar que há uma efetiva necessidade de redução das despesas públicas, é importante distinguir como, para quem e para que fazê-lo. ${ }^{31}$
}

Portanto, constatado o enfraquecimento do Estado no plano econômico, devido essencialmente à escassez de recursos, não há que se pensar que as necessidades sociais devam deixar de ser atendidas, ou que os serviços públicos deixarão de ser prestados. É necessário buscar uma opção mais inteligente para que o Estado garanta os direitos individuais e sociais mínimos, sem que, com isso, entre em colapso. E uma das abordagens que o Direito buscou para responder a esta realidade social foi o instrumento da regulação dos setores econômicos.

\section{2 - A ASCENSÃO DO ESTADO REGULADOR NA ORDEM JURÍDICA}

\section{BRASILEIRA}

\footnotetext{
${ }^{29}$ LEYS, Colin. A Política a Serviço do Mercado. Rio de Janeiro: Record, 2004, p. 13.

${ }^{30}$ BAUMAN, Zygmunt. Modernidade Líquida. Rio de Janeiro: Jorge Zahar Editor, 2001. P. 11.

${ }^{31}$ ARAGÃO, Alexandre Santos. Agências Reguladoras e a Evolução do Direito Administrativo Econômico.

$2^{\mathrm{a}}$ Edição. Rio de Janeiro: Editora Forense, 2003, p.68.
} 
O termo "regulação" traz consigo uma pesada carga de debate doutrinário. Alguns autores, como Diogo de Figueiredo Moreira Neto, entendem que existe uma função reguladora, normas reguladoras e intervenção estatal reguladora ${ }^{32}$. Outros autores fazem a distinção entre regulação, regulamentação, auto-regulação e desregulação ${ }^{33}$. Para além deste problema terminológico, ficaremos com o conceito conclusivo apresentado por Alexandre dos Santos Aragão, pela sua didática e abrangência.

Portanto, a regulação aqui estudada será a regulação estatal da economia, que é:

O conjunto de medidas legislativas, administrativas e convencionais, abstratas ou concretas, pelas quais o Estado, de maneira restritiva da liberdade privada ou meramente indutiva, determina, controla, ou influencia o comportamento dos agentes econômicos, evitando que lesem os interesses sociais definidos no marco da Constituição e orientando-os em direções socialmente desejáveis. ${ }^{34}$

Este conceito é fruto de uma visão mais moderna de Estado, já que este poderá influenciar o comportamento dos agentes econômicos - ou seja, a atuação estatal meramente coercitiva já não é mais a única possibilidade de atuação. Destarte, o perfil da regulação que analisaremos neste trabalho é um perfil contemporâneo, ligado a uma visão mais arrojada do papel do Estado - o que é bom que se destaque, visto que o instituto da regulação é bem mais antigo e já sofreu várias transformações até chegar à concepção apresentada por este administrativista.

Dessa maneira, faremos um corte histórico a partir do fim da década de oitenta, quando assistimos à gradativa diminuição do Estado e o avanço do processo globalizatório, com suas respectivas consequiências sociais e econômicas. Diante desta nova realidade, os juristas buscaram redesenhar os traços tradicionais da Administração Pública, tendo como norte o Princípio da Eficiência, já consagrado no art. 37 da Constituição, porém sob uma nova perspectiva:

A palavra chave dos processos de mudança políticos, sociais e econômicos, introduzidos pela globalização no Estado em mutação é eficiência.

Não se trata mais apenas da eficiência bélica do Estado, que foi tão importante para a atuação externa na era das grandes potências, mas de uma nova e peculiar eficiência política, requerida para dialogar e convencer nos foros multilaterais regionais e mundiais; não mais apenas da tradicional eficiência econômica, entendida como simples aumento de produção com redução do custo de insumos e

\footnotetext{
32 MOREIRA NETO, Diogo de Figueiredo. Mutações do Direito Público. Rio de Janeiro: Editora Renovar. P. 385-427.

${ }^{33}$ ARAGÃO, Alexandre Santos. Agências Reguladoras e a Evolução do Direito Administrativo Econômico. $2^{\text {a }}$ Edição. Rio de Janeiro: Editora Forense, 2003. Capitulo I.

${ }^{34}$ ARAGÃO, Alexandre Santos. Agências Reguladoras e a Evolução do Direito Administrativo Econômico. $2^{a}$ Edição. Rio de Janeiro: Editora Forense, 2003, p. 37.
} 
aumento de lucros, mas, muito além disso, de uma eficiência socioeconômica capaz de produzir bens e serviços de melhor qualidade, mais rapidamente e em maior quantidade, para atender a sociedades cada vez mais demandantes; não mais apenas da eficiência burocrática, mas, necessariamente acrescida a ela, de uma eficiência democrática, demandada por sociedades aptas a identificar seus problemas e a participar de suas soluções; e, também, não mais apenas da eficiência limitada ao âmbito da atuação de Estados isolados, mas da eficiência comunitária, requerida para a atuação cooperativa no concerto regional de Estados solidários. ${ }^{35}$

Assim, o Estado não se destina mais primordialmente à eficiência na produção de superávits econômicos, essencial para o antigo modelo. Ele passa a se concentrar em novas modalidades de eficiência, a ser realizada de forma mais fluída e holística, integrada com novos fatores sociais e econômicos que não mais podem tolerar a intervenção direta e centralizadora que antes existia.

Estes são os paradigmas que informam o nascimento do Estado gerencial brasileiro, "flexível e eficiente", "voltado para o atendimento do cidadão" - expressões utilizadas no Plano Diretor da Reforma do Aparelho do Estado, de $1995^{36}$.

Aliás, trata-se do cumprimento de uma vocação que já existia desde 1988, já que a redação do texto constitucional no seu artigo 174, constante no capítulo de princípios gerais da atividade econômica, estabelece que o Estado atue "como agente normativo e regulador da atividade econômica", exercendo, na forma da lei, "as funções de fiscalização, incentivo e planejamento, sendo este determinante para o setor público e indicativo para o setor privado.”

Na mesma esteira do Plano Diretor da Reforma do Aparelho do Estado, em 1995 entra em vigor a Lei Federal $n^{\circ}$ 8987, conhecida como Lei das Concessões, que também possui como tônica o Estado atuando como gestor. Apenas à guisa de ilustração, destacamos seu artigo 29, que estabelece os encargos do Poder Concedente:

Art. 29. Incumbe ao poder concedente:

I - regulamentar o serviço concedido e fiscalizar permanentemente a sua prestação;

II - aplicar as penalidades regulamentares e contratuais;

III - intervir na prestação do serviço, nos casos e condições previstos em lei;

IV - extinguir a concessão, nos casos previstos nesta Lei e na forma prevista no contrato;

V - homologar reajustes e proceder à revisão das tarifas na forma desta Lei, das normas pertinentes e do contrato;

VI - cumprir e fazer cumprir as disposições regulamentares do serviço e as cláusulas contratuais da concessão;

\footnotetext{
${ }^{35}$ MOREIRA NETO, Diogo de Figueiredo. Mutações do Direito Público. Rio de Janeiro: Editora Renovar, 2002. P.250.

${ }^{36}$ Retirado da obra de DI PIETRO, Maria Sylvia Zanella. Parcerias na Administração Pública. Concessão, Permissão, Franquia, Terceirização, Parceria Público-Privaada e Outras Formas. $5^{a}$ edição. São Paulo: Editora Atlas, 2006. P. 49.
} 
VII - zelar pela boa qualidade do serviço, receber, apurar e solucionar queixas e reclamações dos usuários, que serão cientificados, em até trinta dias, das providências tomadas;

VIII - declarar de utilidade pública os bens necessários à execução do serviço ou obra pública, promovendo as desapropriações, diretamente ou mediante outorga de poderes à concessionária, caso em que será desta a responsabilidade pelas indenizações cabíveis;

IX - declarar de necessidade ou utilidade pública, para fins de instituição de servidão administrativa, os bens necessários à execução de serviço ou obra pública, promovendo-a diretamente ou mediante outorga de poderes à concessionária, caso em que será desta a responsabilidade pelas indenizações cabíveis;

$\mathrm{X}$ - estimular o aumento da qualidade, produtividade, preservação do meioambiente e conservação;

$\mathrm{XI}$ - incentivar a competitividade; $\mathrm{e}$

XII - estimular a formação de associações de usuários para defesa de interesses relativos ao serviço.

Observe-se que a lei utiliza em muitos de seus incisos verbos como "regulamentar", "zelar", "estimular", "incentivar" e novamente "estimular", que são verbos mais intimamente ligados ao Estado atuando como um agente que influencia o comportamento dos atores econômicos do que ao Estado atuando de maneira mais direta e centralizadora (embora, naturalmente, esta função não possa desaparecer de vez, conforme atestam os incisos II, III, IV, V, VIII e IX).

É o mesmo espírito constante na Lei Federal n 9472/97, conhecida como a Lei da ANATEL. Esta é uma lei federal, ou seja, aplica-se tão-somente à Administração Pública Federal; no entanto, defendemos que seu Livro I, intitulado como "Princípios Fundamentais", é considerado norma geral, justamente por trazer princípios, servindo como diploma normativo para todos os entes da federação. Portanto, esta norma geral assim dispõe em seus artigos primeiro e segundo:

Art. $1^{\circ}$ Compete à União, por intermédio do órgão regulador e nos termos das políticas estabelecidas pelos Poderes Executivo e Legislativo, organizar a exploração dos serviços de telecomunicações.

Parágrafo único. A organização inclui, entre outros aspectos, o disciplinamento e a fiscalização da execução, comercialização e uso dos serviços e da implantação e funcionamento de redes de telecomunicações, bem como da utilização dos recursos de órbita e espectro de radiofrequiências.

Art. $2^{\circ}$ O Poder Público tem o dever de:

I - garantir, a toda a população, o acesso às telecomunicações, a tarifas e preços razoáveis, em condições adequadas;

II - estimular a expansão do uso de redes e serviços de telecomunicações pelos serviços de interesse público em benefício da população brasileira;

III - adotar medidas que promovam a competição e a diversidade dos serviços, incrementem sua oferta e propiciem padrões de qualidade compatíveis com a exigência dos usuários;

IV - fortalecer o papel regulador do Estado;

$\mathrm{V}$ - criar oportunidades de investimento e estimular o desenvolvimento tecnológico e industrial, em ambiente competitivo;

VI - criar condições para que o desenvolvimento do setor seja harmônico com as metas de desenvolvimento social do País. (grifos nossos) 
Evidencia-se, dessa forma, o papel regulador do Estado, já apontado pela redação dos dispositivos do art. 29 da Lei Federal $n^{\circ}$ 8987/95, possuindo, portanto, uma atuação muito mais organizadora do mercado do que efetivamente prestadora de serviços públicos ou de interesse público.

Assim, vemos que o Estado despe-se da sua roupagem de atuação direta na economia para assumir, em meados da década de 90, o papel de Estado gestor, realizando uma vocação que já estava presente na Carta Magna de 1988, e que passou a ser corroborada pelas legislações infraconstitucionais editadas posteriormente.

Para além dos debates ideológicos existentes em função da privatização - ou desestatização - sofrida pelo Estado, ela foi um fenômeno que ocorreu em função de diversos fatores econômicos e sociais, e que agora já resta assente no novo papel assumido pelo Estado.

\title{
3.3 - OS NOVOS PARADIGMAS DO DIREITO ADMINISTRATIVO
}

A transformação do Estado de centralizador e realizador da atividade econômica para gestor e regulador foi acompanhada de uma substantiva alteração no Direito Administrativo.

Esta mudança, aliás, já era bem necessária. Conforme ensina Diogo de Figueiredo Moreira Neto:

\begin{abstract}
Mas, enquanto a partir do legado inglês, a evolução da função legislativa e da função judicial assinalavam uma crescente harmonização entre a sociedade e o estado, pavimentando nos últimos duzentos anos o desenvolvimento de uma sólida teoria de direitos fundamentais e do primado da cidadania, por outro lado, de modo paradoxalmente discrepante, a função administrativa, que alojava o cerne da atividade de governo, manteria ainda durante muito tempo a velha postura imperativa, herdada dos tempos do absolutismo, mostrando-se impérvia à absorvição de valores liberais e democráticos, arraigada em conceitos tais como o da preeminência indiscutível das "razões de Estado" e da "supremacia do interesse público", que só começaram a dar mostra de envelhecimento e a ceder no curso do século XX, muito em razão da evolução metodológica do Direito Administrativo em particular. ${ }^{37}$ (grifos nossos)
\end{abstract}

Portanto, novos paradigmas surgem para redesenhar o antigo traçado da Administração centralizadora, legitimada por um "Princípio da Supremacia do Interesse Público" inquestionável, que acabava por justificar decisões arbitrárias e casuísticas contra os

\footnotetext{
${ }^{37}$ FIGUEIREDO MOREIRA NETO, Diogo de. Mutações do Direito Público. Rio de Janeiro: Editora Renovar. P. 63
} 
administrados e por confundir as razões de Estado com o primado do interesse público, ao arrepio de direitos fundamentais dos cidadãos ${ }^{38}$.

Neste mesmo sentido, uma vez mais Diogo de Figueiredo:

O fato inconteste está, porém, no surgimento de uma nova forma de entender o que seja público: não mais como algo inerente e próprio ao Estado, como se havia erigido como um mito poderoso, como nos dá conta Ernest Cassirer, mas como um espaço decisório compartilhado com a sociedade, o que rompe um presumido $\underline{\text { monopólio estatal sobre certas funções de interesse transindividual }}^{39}$. (grifos nossos)

O fenômeno, por ser recente, ainda é objeto da análise de muitos juristas, adquirindo um sem-número de nomenclaturas e perspectivas. Embora o debate doutrinário seja saudável, pois, como já dizia Nelson Rodrigues, toda unanimidade é burra, por uma questão didática utilizaremos apenas aquelas que entendemos ser as características mais representativas dessa mudança, e que encontram algum consenso na doutrina administrativista.

Desta sorte, destacaremos as seguintes características: administração policêntrica, consensualidade, permeabilidade e novas modalidades de legitimação.

\section{(i) - Administração Policêntrica}

A Administração Pública deixa de ser piramidal, de hierarquia fechada, e torna-se policêntrica, em formato de redes fluídas e descentralizadas. Este é o entendimento defendido por Diogo de Figueiredo Moreira Neto:

A transformação das estruturas hierarquizadas e piramidais em estruturas em rede acompanha a evolução da própria sociedade, que passa das tradicionais formas estamentais e hierarquizadas, que eram monoclasses ou biclasses, às modernas conformações mutáveis e flexíveis, ditas pluriclasses, de modo que estas só podem ser concebidas em função de uma muticonfiguraçãocambiante de interesses e de papéis desempenhados pelas pessoas. ${ }^{40}$

E, no mesmo sentido, Gustavo Binembojm:

As autoridades independentes rompem o modelo tradicional de recondução direta de todas as ações administrativas ao governo (decorrente da unidade da Administração). Passa-se, assim, de um desenho piramidal para uma configuração policêntrica. $^{41}$

E também Alexandre dos Santos de Aragão:

\footnotetext{
${ }^{38}$ Nesse sentido ver SARMENTO, Daniel. Interesses Públicos vs. Interesses Privados na Perspectiva da Teoria e da Filosofia Constitucional. In: SARMENTO, Daniel (organizador). Interesses Públicos versus Interesses Privados: Desconstruindo o Princípio de Supremacia do Interesse Público. Rio de Janeiro: Lúmen Júris, 2007.

${ }^{39}$ Op. citada. P. 254

${ }^{40}$ Op. citada, p. 410.

${ }^{41}$ BINEMBOJM, Gustavo. Uma Teoria do Direito Administrativo. Rio de Janeiro: Renovar, 2006. Pgn. 22
} 
Vemo-nos diante de um Direito Administrativo mais complexo e plural, que abandonava a idéia de que uma atividade administrativa só e racional na medida em que estiver previamente prevista, detalhadamente normatizada e sujeita uma linha hierárquica; (...) Em todo o mundo, podemos constatar que a Administração Pública caminha para a descentralização em sentido material. ${ }^{42}$

Este fenômeno se dá essencialmente (mas não somente) em função da criação das Agências Reguladoras, conforme explica Gustavo Binembojm:

O sistema político-administrativo dominante no continente europeu e no Brasil desde o século XIX concentra no governo (presidente ou primeiro-ministro e seu gabinete), enquanto órgão superior da Administração pública, poderes de intervenção intra-administrativa sobre o conjunto amplo de órgãos e entidades sob sua chefia, respondendo politicamente perante o parlamento ou diretamente ao povo, conforme o sistema de governo, pelas ações e omissões administrativas, na medida que se encontra habilitado a dirigir, orientar, supervisionar ou controlar as respectivas estruturas organizativas.

Esse modelo, que encontra similar no constitucionalismo brasileiro, acabou erigindo a unidade administrativa em verdadeiro instrumento do princípio democrático e em fator de legitimação da Administração Pública.(....)

Tal sistema entra em crise com a importação, para diversos países da Europa continental e para o Brasil, da figura da agência reguladora independente. (...) As autoridades ou agências independentes quebraram o vínculo de unidade do interior da Administração Pública, eis que a sua atividade passou a situar-se em esfera jurídica externa à da responsabilização política do governo. (...)

A não-submissão das autoridades independentes à linha hierárquica da chefia da Administração Pública tem sido normalmente justificada pela necessidade de dotar a regulação de alguns setores da economia e da vida social de maior neutralidades, profissionalismo e qualificação técnica, objetivo que não se conseguiu atingir em um modelo unitário, onde a atividade administrativa acabava por tornar-se diretamente responsiva à lógica político-eleitoral. ${ }^{43}$

Portanto, é a Agência Reguladora o principal personagem (embora não o único) a desmontar a Administração tradicional centralizada, e dar-lhe uma organização policêntrica, em forma de rede, mais próxima dos problemas a que se destina a resolver - e, portanto, mais apta a fornecer soluções mais rápidas e funcionais para as questões sob sua tutela.

A nova formação da Administração em configurações de rede não significa que os órgãos antigos devem ser desprestigiados. Ao contrário, deve-se buscar uma integração entre os novos centros de poder da Administração e os organismos antigos - ponto que será fundamental no capítulo seguinte deste trabalho.

\section{(ii) - Consensualidade}

\footnotetext{
${ }^{42}$ Obra citada, p. 211-212.

${ }^{43}$ Obra citada. P. 21-22.
} 
A consensualidade é a possibilidade de participação dos agentes econômicos e sociais na elaboração do ato administrativo. Tradicionalmente, o ato discricionário obedecia tãosomente à conveniência e oportunidade do administrador, apoiado na supremacia do interesse público. No entanto, se partirmos da lógica de que a supremacia do interesse público deve ser ponderada com o respeito aos direitos fundamentais do administrado, é bem razoável que este participe da elaboração do ato administrativo, informando a Administração das suas necessidades para que esta as compatibilize com as necessidades públicas.

Do mesmo entendimento é Diogo de Figueiredo Moreira Neto, cuja obra uma vez mais transcrevemos:

\begin{abstract}
O campo privilegiado da consensualidade é o político, mas tem sido no campo administrativo que aparece abrindo espaços com maior largueza, propiciando o ressurgimento de antigos instrumentos contratuais que haviam caído em desuso, como é o caso das concessões de serviços públicos e de bens públicos e do desenvolvimento de novos e imaginativos instrumentos contratuais e complexos, como a concessão de obras públicas precedendo a de serviços, os concursos financeiros (project financing), as novas parcerias público-privadas, os acordos de programa e os acordos substitutivos, entre tantas outras modalidades de disposição pela Administração da própria competência.

A consensualidade, por certo, não estará destinada a substituir as formas tradicionais de ação imperativa do Estado, mas, sem dúvida, representa uma mudança substancial em suas prioridades de atuação, prestigiando o que hoje se vem denominando parceira com a sociedade. ${ }^{44}$ (grifos nossos)
\end{abstract}

E também Alexandre dos Santos Aragão:

A mera previsão legal da possibilidade da Administração atuar coercitivamente não impede que, deixando de agir impositivamente, adote as medidas em comum acordo com os sujeitos envolvidos, desde que naturalmente, os valores em jogo sejam atendidos pelo menos com o mesmo grau de satisfação com o que seriam de forma coercitiva.

(...)

A consensualização analisada diz respeito menos à contratualização do que à concertação, na qual a Administração não deixa de atuar unilateralmente, mas procura, antes de emitir o seu ato unilateral, obter o assentimento do maior numero possível de sujeitos envolvidos. Para tanto, poderá, desde que satisfaça os interesses públicos visados, conformar o conteúdo do ato unilateral a ser futuramente emitido ao máximo de anuência que puder obter sem prejudicar o interesse público. ${ }^{45}$ (grifos nossos e no original)

Dessa forma, desde que não se perca de vista que o Estado pode e deve continuar agindo de forma coercitiva e impositiva, seria possível a participação dos administrados na formação do ato administrativo, ponderando-se a supremacia do interesse público com os direitos fundamentais dos administrados. Esta nova abordagem do Direito Administrativo

\footnotetext{
${ }^{44}$ Obra Citada. P. 262

${ }^{45}$ Obra Citada. P. 111.
} 
também será essencial para os capítulos seguintes, razão pela qual é importante que esta idéia fique consignada desde já.

\section{(iii) - Permeabilidade}

A permeabilidade é a capacidade que a norma tem de permitir que outros elementos que não o meramente jurídico façam parte da sua concepção. As leis formais, que passam pelo processo legislativo tradicional, perdem um pouco esta capacidade, não apenas pelo seu lento processo de elaboração, como também pela distância entre o legislador e a questão em concreto.

No entanto, se pensarmos em uma Administração com um desenho policêntrico, em que diversos centros de poder atuam mais próximos aos administrados, e voltada para o consensualismo, em que os administrados possuem algum grau de interferência na formação do ato administrativo, a penetração de fatores sociais e econômicos não apenas é possível, mas também, em certos casos, até bem-vinda - conforme restará comprovado no capítulo 3 deste trabalho.

Destacamos, ainda, que a permeabilidade não significa que a Administração Pública irá servir puramente a interesses econômicos. Sabendo da força que os agentes econômicos possuem dentro do sistema capitalista, o jurista deve zelar sempre por uma visão holística, em que diversos fatores devem ser levados em consideração.

Para ilustrar este pensamento, trazemos o seguinte exemplo: um plano de saúde deve pagar pela internação de um assegurado na UTI de um hospital particular. Dados os altos custos deste atendimento, o plano recusa-se a fazê-lo, sendo, por isso, punido em juízo por uma multa diária. Porém, a multa diária é inferior à despesa que se teria com a internação do assegurado na UTI, fazendo com que o plano de saúde prefira pagar a multa a oferecer o benefício necessário para a manutenção da saúde do assegurado.

Neste caso, a intervenção jurídica que não sopesou o fator econômico não atingiu a sua finalidade de garantir o direito à saúde daquele cidadão. Portanto, os fatores econômicos devem permear a atuação da Administração Pública, tendo sempre em vista que o administrador não se pode deixar induzir inteiramente por ele.

\section{(iv) - Novas Modalidades de Legitimação}


Como última característica inovadora do Direito Administrativo hodierno, destacamos as novas modalidades pela qual este busca legitimar-se. Esta última característica decorre como conclusão das demais características apresentadas.

Se há uma participação maior do administrado na elaboração do ato administrativo, tem-se uma nova fonte de legitimidade, uma vez que o cidadão não mais será representado indiretamente por um legislador frio e distante, com os problemas conhecidos do desacreditado sistema político nacional.

Por esta nova concepção de Administração Pública, o cidadão terá espaço para participar da confecção dos atos administrativos, tendo suas razões ouvidas pelo administrador, que se tornará ainda mais legitimado em suas ações ao assim proceder. É o pensamento de Diogo Figueiredo Moreira Neto, cujas percepções acerca das mutações do Direito Público já citamos tantas vezes:

Embora, originalmente, nas sociedades monoclasse e biclasse houvesse bastado uma modalidade de participação reduzida à escolha dos agentes políticos, parece hoje fora de dúvida que a complexidade dos problemas e das soluções políticas demanda novas formas de participação voltadas à escolha de políticas públicas, dotadas de grau de diferenciação suficiente para atender às especificidades dos diversos subgrupos sociais reivindicantes. Esta diferença é sumamente importante para se aferir não apenas o grau de eficiência juridicamente estimável dessas políticas, como, e principalmente, o seu grau de efetividade social. ${ }^{46}$ (grifos nossos)

E ainda Alexandre dos Santos Aragão, que transcrevemos uma vez mais:

Neste contexto, muito mais do que aferir a legitimidade da regulação pela sua subsunção lógico-formal a determinado preceito legislativo, deve ser verificado o atendimento às finalidades públicas a que se destina. Ao esquema, não mais predominante no Direito Público, de preceito-sanção, devemos agregar o de objetivo meio-eficaz.

Em segundo lugar, como legitimação do processo decisório, devem ser adotadas medidas capazes de suprir o déficit de democraticidade da regulação administrativa criando um 'espaço público de discussão', mediante, por exemplo, a participação pública na edição dos atos normativos e a obrigação da Administração, ao expedir o regulamento, motivar as recusas à sugestão e críticas da coletividade.

(...)

Ainda como requisito da legitimidade da Administração Pública da economia, temos a imposição dela se pautar de acordo com os princípios do Estado Democrático de Direito e da Administração Pública, notadamente com os princípios da razoabilidade e da eficiência, restringindo os direitos e interesses, individuais e coletivos, apenas à medida que seja capaz de atingir com eficiência os fins públicos legitimamente almejados. ${ }^{47}$ (grifos nossos e no original)

\footnotetext{
${ }^{46}$ Obra Citada. P. 69.

${ }^{47}$ Obra Citada. P. 104-105.
} 
Esta compreensão é essencial para a atuação das Agências Reguladoras na proteção ao meio ambiente. Frise-se, aliás, que o Direito Ambiental já há muito conhece esses novos mecanismos de legitimação, em especial pelo uso das audiências públicas ${ }^{48}$.

A participação pública não apenas legitima o administrador a normatizar determinada matéria, como também o orienta quanto à solução mais próxima do interesse público - e mais garantidora dos direitos fundamentais do administrado - que poderá ser tomada no caso concreto. Afinal, por mais funcional que um órgão possa ser, nem sempre todos os fatores envolvidos na questão são puramente técnicos, sendo saudável que se ouça a população em determinados casos concretos - sem que se perca a visão da questão como um todo e dos deveres e limitações institucionais do Estado.

Concluímos, portanto, esta parte deste primeiro capítulo ressaltando que essas mudanças no Direito Administrativo são extremamente necessárias. Algumas delas até já eram pensadas por alguns doutrinadores anteriormente; porém, com a mudança de paradigma do Estado, que deixou de atuar diretamente na atividade econômica para se tornar gestor, e com a ascensão das Agências Reguladoras, essas mudanças vão, aos poucos, sendo efetivadas na prática.

Compete-nos, agora, pensar como estes novos elementos da Administração Pública irão relacionar-se com os órgãos da Administração tradicional, que têm mesmo mais dificuldade para incorporar essas mudanças de paradigma. Talvez as Agências Reguladoras possam capitanear uma mudança de pensamento dentro de toda a Administração, propondo uma atuação mais eficiente da máquina estatal.

\section{4 - CONCLUSÃO: O MODELO DE DESENVOLVIMENTO SUSTENTÁVEL}

Conforme foi debatido na primeira parte deste artigo, o Direito Ambiental precisa ser enxergado também como parte do Direito Econômico, com especial ênfase à prevenção dos danos ambientais. Não considerar o aspecto econômico na proteção dos elementos naturais não irá protegê-los, mas sim acarretará em uma utilização desenfreada destes recursos pelos agentes econômicos.

De mais a mais, não se pode proteger a Natureza de forma a impedir o desenvolvimento econômico - mas esse desenvolvimento deve ser pensado de forma que

\footnotetext{
${ }^{48}$ Estatuto da Cidade, art.40, §4 , I; Resolução CONAMA 1/86, em relação à elaboração do EIA/RIMA; Art. 22, $\S 2^{\circ}$, Lei Federal n 9985/00, em relação à criação de Unidades de Conservação.
} 
todos os atores sociais sejam beneficiados, buscando um ponto de equilíbrio através da fórmula do desenvolvimento sustentável.

Por outro lado, o Direito Econômico assume uma nova perspectiva no ordenamento brasileiro após a década de oitenta, eis que houve uma mudança no perfil do Estado, consagrada no art. 174 da Constituição e em alguns diplomas infraconstitucionais posteriores, seja de maneira direta, seja pela interpretação teleológica dos seus artigos.

A ascensão do Estado regulador acabou por introduzir mudanças no Direito Administrativo, fenômeno que ainda não possui consenso na doutrina quanto a suas peculiaridades, mas que possui algumas características que podemos, desde já, destacar: administração policêntrica, consensualidade, permeabilidade e novas modalidades de legitimação.

Portanto, constadas as mudanças que expusemos até aqui, resta-nos a indagação: como esse novo Estado Regulador, cuja Administração é agora regida por novos parâmetros teóricos, atuará em um dos campos fundamentais do Direito Econômico, que é o Direito Ambiental? Ou, colocado de outra maneira: as Agências Reguladoras, protagonistas de grande parte destas mudanças, podem chamar o Direito Ambiental a uma atuação mais eficiente?

Esta preocupação também já foi externada por Paulo de Bessa Antunes:

\begin{abstract}
Quanto à regulação ambiental das empresas privatizadas, a questão que se coloca é a de saber se o modelo de controle ambiental atualmente existente no Brasil deve ser aplicado às empresas concessionárias de serviços públicos que foram privatizadas. Este é um problema relevante, pois a boa qualidade ambiental e a própria continuidade da prestação dos serviços públicos a ela estão vinculadas. ${ }^{49}$
\end{abstract}

Concordamos inteiramente com Paulo de Bessa. As questões ambientais são tão fundamentais aos serviços públicos concedidos como quaisquer outras. Corroborando este pensamento, veja-se o art. $6^{\circ}$ e seu $\$ 1^{\circ}$, da Lei Federal $n^{\circ} 8987 / 95$, que traz a necessidade da prestação de serviço adequado, conforme segue abaixo:

Art. $6^{\circ}$ Toda concessão ou permissão pressupõe a prestação de serviço adequado ao pleno atendimento dos usuários, conforme estabelecido nesta Lei, nas normas pertinentes e no respectivo contrato.

$\S 1^{\underline{0}}$ Serviço adequado é o que satisfaz as condições de regularidade, continuidade, eficiência, segurança, atualidade, generalidade, cortesia na sua prestação e modicidade das tarifas.

E não há que se pensar um serviço seguro, contínuo e eficiente que não leve em consideração as questões ambientais. Assim, a redação deste artigo da Lei de Concessões coaduna-se com o entendimento defendido por Paulo de Bessa: as questões ambientais são

\footnotetext{
${ }^{49}$ ANTUNES, Paulo de Bessa. Direito Ambiental. 9a Edição. Rio de Janeiro: Editora Lúmen Júris, 2006. P. 169
} 
fundamentais para o serviço público concedido, como o são para qualquer outra atividade econômica.

Neste contexto, o tema da regulação, que é ainda muito recente no Direito brasileiro, pode ser abordado sob a perspectiva teórica apresentada neste trabalho, ainda que os entes reguladores sofram com a ausência de paradigmas teóricos orientadores da sua atuação perante os casos concretos.

Porém, a lacuna destes referenciais teóricos não deve paralisar a atuação destes órgãos. É dever dos juristas procurar por soluções inteligentes e sensíveis à realidade social par os problemas que se afiguram.

Estas soluções, no entanto, não podem ser fruto da satisfação pessoal de alguns grupos econômicos e políticos, apresentando respostas parciais e autoritárias a problemas que demandam uma ponderação maior sobre diversos aspectos. Há que se respeitar os novos valores levantados não apenas em sede de Direito Administrativo, como alguns dos que foram apresentados neste trabalho, mas também valores sociais e econômicos - especialmente em se tratando da questão ambiental.

Portanto, o jurista deve estar atento à percepção de quais são estes valores e como eles funcionam na prática. Enxergar os bens ambientais como bens econômicos, por exemplo, permite que se encontre um meio termo entre desenvolvimento e preservação, oferecendo soluções que realmente funcionem na prática. Cercar a natureza em uma "bolha legal" e não permitir a aproximação de ninguém gera apenas um preciosismo legal e uma fragilidade real destes bens, que continuarão a ser explorados pelas forças econômicas de maior pressão, à revelia das boas intenções contidas no papel.

\section{5 - REFERÊNCIAS BIBLIOGRÁFICAS:}

ANTUNES, Paulo de Bessa. Direito Ambiental. $9^{a}$ Edição. Rio de Janeiro: Editora Lúmen Júris, 2006.

Dano Ambiental: Uma Abordagem Conceitual. $1^{\text {a }}$ Edição. Rio de Janeiro: Editora Lúmen Júris, 2002.

ARAGÃO, Alexandre Santos. Agências Reguladoras e a Evolução do Direito

Administrativo Econômico. $2^{\text {a }}$ Edição. Rio de Janeiro: Editora Forense, 2003.

BAUMAN, Zygmunt. Modernidade Líquida. Rio de Janeiro: Jorge Zahar Editor, 2001. 
DI PIETRO, Maria Sylvia Zanella. Parcerias na Administração Pública. Concessão, Permissão, Franquia, Terceirização, Parceria Público-Privaada e Outras Formas. $5^{\text {a }}$ edição. São Paulo: Editora Atlas, 2006.

BINEMBOJM, Gustavo. Uma Teoria do Direito Administrativo. Rio de Janeiro: Renovar, 2006.

FIORILLO, Celso Antonio Pacheco. A Natureza Jurídica do Bem Ambiental. Em: http://www.fiorillo.com.br/site/. Acesso em janeiro de 2008.

GRAU, Eros. A Ordem Econômica na Constituição de 1988. $11^{\circ}$ edição. São Paulo: Malheiros Editores, 2006.

LEYS, Colin. A Política a Serviço do Mercado. Rio de Janeiro: Record, 2004

MACHADO, Paulo Affonso Leme. Direito Ambiental Brasileiro. 14 Edição. São Paulo:

Malheiros Editores, 2006.

MAY, Peter. Certificação Florestal No Brasil: Valorização Comercial e Ambiental. Em http://www.wto.org/english/forums_e/ngo_e/ccc_cert_forest_brazil_p.doc. Acesso em janeiro de 2008.

MICHELS, Ruanda Schlickmann Michels. Instrumentos administrativos de prevenção ao dano ambiental. Revista de Direito Ambiental 45. Rio de Janeiro: Editora Revista dos Tribunais, 2007.

MILARÉ, Édis. Direito do Ambiente: Doutrina - Jurisprudência - Glossário. $4^{\text {a }}$ Edição. São Paulo: Editora Revista dos Tribunais, 2005.

MOREIRA NETO, Diogo de Figueiredo. Mutações do Direito Público. Rio de Janeiro: Editora Renovar, 2002.

MUKAI, Toshio. Direito Ambiental Sistematizado. $6^{\text {a }}$ Edição. Rio de Janeiro: Forense Universitária, 2007.

SARMENTO, Daniel. Interesses Públicos vs. Interesses Privados na Perspectiva da Teoria e da Filosofia Constitucional. In: SARMENTO, Daniel (organizador). Interesses Públicos versus Interesses Privados: Desconstruindo o Princípio de Supremacia do Interesse Público. Rio de Janeiro: Lúmen Júris, 2007.

TORRES, Ricardo Lobo. Tratado de Direito Constitucional Financeiro e Tributário. Volume II - Valores e Princípios Constitucionais Tributários. Rio de Janeiro: Ed. Renovar, 2005.

SILVA, José Afonso da. Direito Ambiental Constitucional. 5a Edição. São Paulo: Editora Malheiros, 2004. 